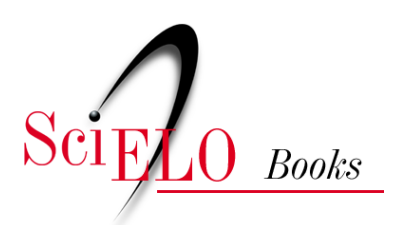

\title{
3. Tipologías de clientelismo
}

\author{
Laura Daniela Guerrero García
}

GUERRERO GARCÍA, L.D. Tipologías de clientelismo. In: Clientelismo político, ¿desviación de la política o forma de representación?: Estado del arte sobre las aproximaciones al clientelismo en Colombia 1973-2011 [online]. Bogotá: Editorial Universidad del Rosario, 2014, pp. 47-53. Opera prima collection. ISBN: 978-958-738-552-6. https://doi.org/10.7476/9789587385526.0005.

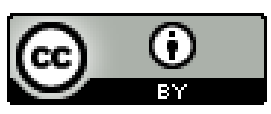

All the contents of this work, except where otherwise noted, is licensed under a Creative Commons Attribution 4.0 $\underline{\text { International license. }}$

Todo o conteúdo deste trabalho, exceto quando houver ressalva, é publicado sob a licença Creative Commons Atribição 4.0.

Todo el contenido de esta obra, excepto donde se indique lo contrario, está bajo licencia de la licencia $\underline{\text { Creative }}$ Commons Reconocimento 4.0 . 


\section{Tipologías de clientelismo}

Si bien la literatura señala que el fenómeno del clientelismo ha sido observado desde el siglo xIx en Colombia, no siempre se hace referencia al mismo tipo de fenómeno. De hecho, las transformaciones en las condiciones económicas, sociales y de los regímenes políticos ha generado consenso entre los mismos autores al identificar tres tipos de clientelismo. Por ejemplo, durante el siglo xIx, los recursos base del intercambio clientelista eran tanto públicos como privados debido a la débil capacidad fiscal del Estado de la época. ${ }^{64}$ Durante el siglo xx, en cambio, el aumento de la capacidad de recaudo estatal hizo que las clientelas empezaran a ser sostenidas exclusivamente con recursos públicos. No obstante, en los años ochenta se observó que los recursos públicos no alcanzaban a cubrir la totalidad de las demandas de las redes clientelistas y se le abrió la puerta a capitales privados (no del todo lícitos) en las dinámicas políticas.

Estos cambios en la naturaleza del intercambio de las relaciones clientelistas permiten plantear tres tipos de clientelismo: ${ }^{65}$ el tradicional, que se presentó a lo largo del siglo xix y parte del xx; el moderno, que estuvo presente a lo largo de la segunda mitad del siglo xx; y el de mercado, estudiado especialmente para el caso de Bogotá post Constitución de 1991. A continuación se presenta cada tipología y los debates teóricos que las acompañaron.

${ }^{64}$ Comparar Torres Preciado, "Vicio”, 18.

${ }^{65}$ Estas tres categorías ad hoc fueron formuladas por los diferentes autores. Se observa que existe consenso alrededor de las mismas. 


\subsection{Clientelismo tradicional}

El clientelismo tradicional fue estudiado a partir de los trabajos sobre caciquismo y patronazgo de autores tales como Malcolm Deas y Fernando Guillén Martínez. El estudio de este tipo de clientelismo partió de la revisión de las instituciones coloniales. Al respecto, Guillén Martínez encuentra que el caudillismo y el clientelismo son formas de asociación política con génesis en la encomienda. Esta figura generó lealtades feudales a partir de pactos tácitos sobre el intercambio de prestaciones y contraprestaciones, y es antecedente de la hacienda, figura que logró proyectarse hasta mediados del siglo xx y se caracterizó por presentar un intercambio casi exclusivo entre el patrón, gamonal o cacique y el cliente, siervo o campesino. Se trataba de una relación diádica, personal y directa, donde los recursos comprometidos provenían del acervo patrimonial y privado del patrón. En el clientelismo de corte tradicional, el Estado no ocupaba un papel central en la relación y en el sistema de adhesiones y lealtades. ${ }^{66}$

Desde una postura institucionalista, se señaló que las formas de asociación del siglo xix superaron el espacio temporal de la encomienda de tal manera que se trasladaron al espacio temporal de la hacienda. Lo anterior es la razón por la cual los hacendados fueron los mismos que conformaron los dos partidos políticos tradicionales. Se sigue la senda del pasado de manera que las élites políticas regionales lograron mantenerse en el juego por el control del Estado. El traslado del modelo de la hacienda al Estado implicó, a su vez, el tránsito de un tipo de dominación patrimonial a uno de dominación burocrática. El Estado se convirtió en el patrón de los patrones y estos, a su vez, pasaron a ser meros intermediarios. Con ello se efectuó un desplazamiento hacia un

\footnotetext{
${ }^{66}$ Comparar Dávila Ladrón de Guevara, “Clientelismo, intermediación”, 65-66.
} 
tipo diferente de clientelismo. En este, los políticos, la burocracia y el Estado empiezan a ser los protagonistas. Se trata, entonces, de un clientelismo moderno, burocrático o estatal. Este tránsito del clientelismo tradicional al moderno se dio durante el Frente Nacional. Sin embargo, algunas características del régimen (tales como su aspecto cerrado, excluyente y oligárquico) tienen sus orígenes en estas primeras formas de asociación, las cuales pese a las rupturas presentan continuidades hasta el presente.

\subsection{Clientelismo moderno}

El clientelismo moderno es la tipología con mayor frecuencia abordada por los autores que trabajan la temática. Este hace referencia al fenómeno que alcanzó grandes proporciones dentro del sistema político colombiano; es decir, a aquel contra el cual Carlos Lleras Restrepo emprendió su lucha cuando publicó, en el diario Nueva Frontera, un artículo titulado "Las elecciones sucias y otras $\operatorname{cosas}{ }^{67}$ que, posteriormente, trató de ser erradicado vía reformas constitucionales.

El montaje del clientelismo moderno se surtió a lo largo del Frente Nacional y tuvo su punto máximo de concreción a partir de la reforma de 1968. ¿Qué generó el paso de un tipo de clientelismo a otro? Eduardo Díaz explica que a raíz del modelo cepalino de sustitución de importaciones, implementado desde mediados del siglo $\mathrm{xx}$, se "[...] liberó a amplios sectores de las relaciones de servidumbre $[\ldots]$ de los gamonales y jefaturas políticas tradicionales, ubicándolos en las barricadas y cinturones de miseria de las grandes ciudades o centros industriales". 68

\footnotetext{
${ }^{67}$ Ver Leal Buitrago y Davila Ladrón de Guevara, Clientelismo, 35.

${ }^{68}$ Ver Jaramillo, Clientelismo y poder: relectura, 18.
} 
El cambio de una producción agrícola a una industrial implicó: una mayor urbanización, relaciones económicas monetizadas, diversificación de clases sociales, expansión de las instituciones del Estado, entre otros. ${ }^{69}$ Esto generó una ruptura con las formas tradicionales de organización política en la medida que las relaciones de servidumbre se transformaron en relaciones laborales y las lealtades fueron sustituidas por otros mecanismos de vinculación. Los más afectados fueron los partidos tradicionales, quienes tuvieron que desarrollar mecanismos para defender y solidificar su autoridad en la nueva forma de poder estatal. ${ }^{70} \mathrm{De}$ hecho, el Frente Nacional puede interpretarse como el esfuerzo de tales partidos por mantener su poder, siendo los intermediarios entre la población rural (y algún porcentaje de la urbana) y el Estado, presentándose como únicos proveedores de servicios y bienes públicos.

Cristina Escobar señala, al respecto, que la relación clientelista se caracterizó por ser "[...] periódica, específica, causal, instrumental, y el voto es [fue] el principal bien de intercambio. Por estos motivos, el clientelismo de intermediación debe ser entendido en relación con el Estado, sus instituciones burocráticas, regímenes políticos, estructuras y sistemas de partidos y asociaciones civiles". ${ }^{71}$

El nuevo líder, señala Roll, ya no es el típico terrateniente o comerciante próspero. Ahora, es un individuo que, por lo general, proviene de sectores populares y ha escalado en la maquinaria

${ }^{69}$ Ibid., 25.

${ }^{70}$ Comparar Martz, The Politics, 31.

${ }^{71}$ Ver Cristina Escobar, Clientelism Movilization and Citizenship: Peasant Politics in Sucre, Colombia (Michigan: UMI, Ann Arbor, 1998), 9. 
política. Se trata de un intermediario: es cliente frente al poder central, pero patrón frente a las instancias regionales. ${ }^{72}$

Jorge Valenzuela, en un estudio de caso sobre la producción arrocera en el Huila en 1978, ${ }^{73}$ encuentra que el perfil del líder en el nivel local varía del departamental. En el primer nivel, el líder es más cercano a un clientelismo tradicional, mientras que en el segundo a uno de corte moderno.

En este orden, las categorías de clientelismo tradicional y moderno no necesariamente obedecen a categorías temporales. También pueden obedecer a lógicas espaciales de organización del poder político. ${ }^{74}$ En síntesis, el recorrido realizado da cuenta de que la mayor concentración de estudios sobre el clientelismo lo observan como un fenómeno político moderno. Para el caso colombiano es preciso advertir que si bien el carácter moderno está relacionado con la noción de Estado racional moderno y su aparato burocrático, también es factible observar algunas pautas o herencias previas de formas premodernas, asociadas a las relaciones patronales de la hacienda. Esta observación toma mayor fuerza cuando la unidad de análisis no es lo nacional, sino lo regional y lo local.

\subsection{Clientelismo de mercado}

El clientelismo de mercado es el tercer tipo que emerge tras las reformas introducidas al régimen bogotano a partir de 1991. Mauricio García Villegas señala que el clientelismo de mercado "tiene a los políticos como protagonistas y se vale de la existencia de nuevas

${ }^{72}$ Comparar David Alberto Roll, Rojo difuso y azul pálido (Bogotá: Universidad Nacional de Colombia, 2002), 67.

${ }^{73}$ Comparar Valenzuela Ramírez, Producción, 35-37.

${ }^{74}$ Ibid., 35-37. 
reformas institucionales tales como la descentralización, la elección popular y los mecanismos de participación". ${ }^{75}$

La Constitución de 1991 propendía por la eliminación de todas las prácticas consideradas como atrasadas o clientelistas. Para tal efecto, en la carta política se consagraron medidas en pro de la apertura política del sistema y la profundización democrática del régimen. Nuevas fuerzas y movimientos aparecieron en la escena pública, gracias a la reducción de los umbrales electorales y la flexibilización de los requisitos de acceso a los órganos y cargos de elección popular. Por otra parte, la Constitución prohibió los mecanismos que se creían aceitaban la maquinaria clientelista (entre ellos, los auxilios parlamentarios); estableció incompatibilidades e inhabilidades que limitaban el acceso de políticos clientelistas; colocó topes a la financiación de las campañas electorales; creó el tarjetón e introdujo cambios en las circunscripciones de Senado y Cámara, entre otras disposiciones. Finalmente, la Constitución de 1991 intentó recuperar la función de control político del poder legislativo a partir de figuras como la moción de censura. Sin embargo, el cumplimiento de tales objetivos no logró la eliminación total del clientelismo, sino su adaptación a las nuevas realidades institucionales. ${ }^{76}$

Elclientelismo de mercado, concretamente, se diferencia del moderno en que el líder no cuenta con un gran caudal electoral a nivel nacional, sino, por el contrario, es representante de una red más pequeña, particular y menos asimétrica. La competencia de los intermediarios (políticos) ha crecido, produciendo una gran capacidad de negociación por parte de los clientes. Los elementos ideológicos tienden a desaparecer. La naturaleza de los

${ }^{75}$ Ver García Villegas y Revelo Rebolledo, Estado, 24.

${ }^{76}$ Comparar Dávila Ladrón de Guevara y Delgado Varela, "La metamorfosis”,328-332. 
recursos a intercambiar es tanto pública como privada. Este nuevo modelo, al fraccionar a los partidos en miles de redes clientelistas, ha sido denominado como el modelo de la "micro-empresa electoral". ${ }^{77}$ También, se observa que el clientelismo florece en la creación de otros tipos de identidad tales como la cultural e incluso la religiosa. ${ }^{78}$

El clientelismo de mercado es un fenómeno que hasta ahora sólo se ha analizado en Bogotá, a partir de la Constitución de 1991 y de la proclamación del Estatuto Orgánico que rige a la capital. Los estudios señalan que los cambios institucionales en Bogotá permiten vislumbrar una nueva faceta del clientelismo. En esta, el fenómeno se configura como una forma de hacer política que no está exenta de implementar participación ciudadana y representación política.

\footnotetext{
77 Comparar Eduardo Pizarro Leongómez, "La atomización partidista en Colombia: el fenómeno de las micro-empresas electorales", en Degradación o cambio: evolución del sistema politico colombiano, compilado por Francisco Gutiérrez Sanín (Bogotá: Editorial Norma, 2002).

${ }^{78}$ Comparar también Álvaro Cepeda Van Houten, Neopentecostalismo y política. El caso colombiano (Cali: Universidad de San Buenaventura, 2010); Lucía Eugenia Meneses, "La política Nasa y el clientelismo en el municipio de Páez, Cauca", Revista Colombiana de Antropología e Historia, 38 (2002): 105-130.
} 